\title{
The Flow Through Cell Methodology in the Evaluation of Intralumenal Drug Release Characteristics
}

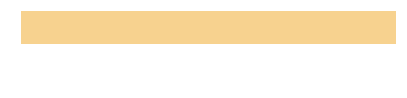

\author{
Nikoletta Fotaki ${ }^{1}$ and Christos Reppas ${ }^{1,2}$
}

email: reppas@pharm.uoa.gr

\begin{abstract}
In this paper the usefulness of the flow through cell apparatus in the evaluation of intralumenal drug release characteristics is reviewed. Initially, the basic characteristics of this setup are presented. Then, the relative advantages and disadvantages of the flow through cell apparatus over other in vitro release setups are summarized. Finally, potential applications of this setup are discussed according to the solubility characteristics of the tested compound and the release characteristics of the dosage form.
\end{abstract}

\section{INTRODUCTION}

he history of the flow through cell methodology in drug release testing of oral dosage forms begins in the 1950's. The first attempt for the development of the flow-cell method was probably made in the laboratories of the U.S. Food and Drug Administration in $1957(1,2)$. Since then, various flow-cell devices have been described (2-7). The flow through cell was recommended as an alternative in vitro drug release testing apparatus by the Dissolution Tests working group of the Fédération Internationale Pharmaceutique (F.I.P.) in 1981 (2). Afterwards, the method was incorporated in various pharmacopoeias (2).

In the USP the flow through cell apparatus is described as Apparatus 4 (8). The assembly consists of a reservoir containing the release medium, a pump that forces the release medium upwards through the vertically positioned flow-cell, and a water bath. The pump usually has a flow rate delivery capacity between 4 and $16 \mathrm{~mL} / \mathrm{min}$, with typical flow rates being 4,8 , and $16 \mathrm{~mL} / \mathrm{min}$. Usually the bottom cone of the cell is filled with small glass beads of about $1 \mathrm{~mm}$ diameter and with one bead of about $5 \mathrm{~mm}$ positioned at the apex to protect the fluid entry tube, whereas a filter (most frequently, a glass-fiber filter) is positioned at the inner top of the cell (8). Most frequently, the flow through cell apparatus is used as an open system with fresh solvent from the reservoir continuously passing through the cell where the dosage form is initially accommodated. However, it is also possible to operate it as a closed system by recycling a fixed volume of liquid. The design of the cell provides welldefined geometry and hydrodynamics. With slight changes in the cell design, the same apparatus can be used for testing of tablets, powders, suppositories, or gelatin capsules, either hard or soft. (8-10). For orally administered solid dosage forms, two different cells are described (8): the large cell $(22.6 \mathrm{~mm}$ i.d.) and the small cell $(12 \mathrm{~mm}$ i.d.). Cell diameters can be associated with flow rates according to the parameters presented in Table $1(2,4)$. It is important to note that linear flow velocity is the parameter that defines hydrodynamic "agitation" of the fluid on the specimen. By

'Laboratory of Biopharmaceutics and Pharmacokinetics, University of Athens, Athens, Greece taking into account the small intestinal transit times and the total length of the small intestine (11-13), the average (estimated) axial velocity is about 1.5 and $1.3 \mathrm{~cm} / \mathrm{min}$ under fasted and fed state conditions, respectively. Using the USP flow through cell apparatus, similar axial velocities correspond to flow rates less than $8 \mathrm{~mL} / \mathrm{min}$ (Table 1 ).

\section{OPEN VS CLOSED IN VITRO DRUG RELEASE SETUPS}

One of the distinct advantages of the flow through cell apparatus over the more traditional closed in vitro setups such as the rotating paddle and the rotating basket apparatus (8) is that media and/or flow rate changes can be easily performed within a single run. This facilitates testing of formulation robustness with respect to variations in intralumenal environment. Furthermore, carry-over effects can be identified and in vitro-in vivo correlations should be easier because a single profile corresponding to the release in the entire gastrointestinal (Gl) lumen is obtainable.

Another advantage of the flow through apparatus when used as an open system is that intralumenal hydrodynamics are more efficiently simulated compared with other in vitro setups. Specifically, when compared with closed systems, it is possible to sustain sink conditions in the flow through apparatus for longer periods. Maintenance of sink conditions is especially important for poorly soluble drugs and,

Table 1: Diameters of the cells used for testing orally administered solid products with the flow through apparatus, cross-sectional areas of the cells and linear flow velocities corresponding to specific flow rates $(2,4)$.

\begin{tabular}{|ccccccc|}
\hline \multirow{2}{*}{$\begin{array}{c}\text { Diameter } \\
(\mathbf{m m})\end{array}$} & $\begin{array}{c}\text { Area } \\
(\mathbf{c m})\end{array}$ & \multicolumn{5}{c|}{ Volumetric flow (mL/min) } \\
\cline { 3 - 7 } & & 2 & 4 & 8 & 16 & 32 \\
\hline 11.3 & 1 & 2 & 4 & 8 & 16 & 32 \\
\hline 22.6 & 4 & 0.5 & 1 & 2 & 4 & 8 \\
\hline
\end{tabular}

${ }^{2}$ Corresponding author, School of Pharmacy, Laboratory of Biopharmaceutics and Pharmacokinetics, University of Athens, Panepistimiopolis, 15771 Zografou, Greece 
therefore, the development of in vitro-in vivo correlations should be easier with the flow through apparatus (14). With closed systems, in vitro-in vivo correlations could also be obtained but in this case the modeling of the in vitro data is necessary (15).

A third advantage might also be that floating or other special dosage forms are more easily studied with the flow through apparatus (16).

A disadvantage of the flow through cell apparatus may be that the use of heterogenous media, such as media simulating the gastric composition in the fed state (17), is problematic, because an efficient filtering process and maintenance of desired flow rates might not be possible.

Finally, a key difference between an open and a closed in vitro release system is that, with the former, raw data are collected in non-cumulative form. Data collected with the flow through cell apparatus are amounts dissolved at specific time intervals (and not at specific time points), so that they can be assumed as rough estimates of release rates. Unless data are used in quality control testing and, therefore, total label claim is of interest, transformation to the cumulative form does not offer any specific advantage whereas any mistake(s) associated with the estimation of the total drug released during a specific time interval will be transferred to the next time interval (18). Further, if a model is to be fitted to the data, by converting them to the cumulative form, the fundamental assumption of independence of errors is violated (18).

\section{THE FLOW THROUGH CELL APPARATUS FOR THE PREDICTION OF THE IN VIVO PERFORMANCE OF ORAL- LY ADMINISTERED DOSAGE FORMS}

\subsection{Immediate Release Dosage forms}

\subsubsection{Drugs with high solubility (19)}

For highly soluble compounds the flow through cell apparatus can be used for the assessment of intralumenal disintegration characteristics.

For example, it has been successfully used for assessing the disintegration of cross-linked gelatin capsules containing amoxicillin (20). Lag times prior to the initiation of dissolution process in media simulating the gastrointestinal contents in the fasted state [Fasted State Simulating Gastric Fluid (21) for $45 \mathrm{~min}$ at $8 \mathrm{~mL} / \mathrm{min}$ followed by FaSSIF (22) for $210 \mathrm{~min}$ at $8 \mathrm{~mL} / \mathrm{min}$ ] were close to in vivo disintegration times of the capsules in the fasted gastrointestinal lumen (23) whereas both in vitro and in vivo data were dependent on the degree of cross-linking of gelatin $(20,23)$.

More recently, it has been shown that dissolution of paracetamol from immediate release formulations with the flow through apparatus is rapid and complete in media simulating the fasted state but it is substantially delayed in media simulating the fed state (24). Dissolution was monitored in milk 3.5\% fat (0-90 min, $6 \mathrm{~mL} / \mathrm{min})(22,25)$, followed by FeSSIF (90-180 min, 6 mL/min) (22). Data collected under these conditions adequately reflected the delayed disintegration times of a commercially available paracetamol tablet in fed dogs (24) and in fed humans (26).

\subsubsection{Drugs with low solubility (19)}

The flow through cell apparatus has been tested for its usefulness in the prediction of food effects on intralumenal dissolution characteristics of poorly soluble compounds and also, since poorly soluble compounds are frequently associated with unproblematic transport through the intestinal mucosa, for its usefulness in the development of correlations between in vitro dissolution data and plasma levels.

It has been shown that the improved in vivo dissolution of spironolactone particles and troglitazone tablets in the fed small intestine can be correctly predicted with the flow through cell apparatus when physiologically relevant media and flow rates are used $(27,28)$.

However, Bonlokke et al. (29) have shown that dissolution profiles of carbamazepine particles obtained using the large flow-cell (8) and physiologically relevant media and flow rates $(2.5 \mathrm{~mL} / \mathrm{min})$ were lower than the in vivo dissolution profiles. Authors attributed the discrepancy to the inability of this apparatus to simulate the complex mixing and flow patterns in the normal gastrointestinal tract (29). In accordance with Bonlokke et al. data, Nicolaides et al. (28) also reported that dissolution profiles of another low solubility weak acid (troglitazone) obtained with the large flow-cell, using FaSSIF (22) at 2.5 and $4 \mathrm{~mL} / \mathrm{min}$ or FeSSIF (22) at 4 and $6 \mathrm{~mL} / \mathrm{min}$ were lower than in vivo absorption profiles (28). These authors also showed that when a troglitazone tablet is initially treated with SGF (0-30 $\mathrm{min}, 12 \mathrm{~mL} / \mathrm{min})(30)$ and then with FaSSIF (30-150 min, $4 \mathrm{~mL} / \mathrm{min}$ ) (22) dissolution is greater in SGF than in FaSSIF; a surprising observation given the ionization and the lipophilicity characteristics of troglitazone. Both the lower in vitro profiles compared to in vivo profiles and the lower dissolution in media with higher $\mathrm{pH}$ and bile salt concentration are attributed to the inadequate simulation of the in vivo hydrodynamics; when simulation of conditions in the small intestinal lumen is targeted, the use of physiologically relevant flow rates and the absence of radial loss (absorption) of the drug may lead to non-sink conditions and, therefore, to lower than in vivo dissolution profiles (28). In addition, possible sedimentation of particles on the lower sides of the cell (due to its vertical position) may also lead to incomplete in vitro dissolution (28).

Sunesen et al. (12) developed in vitro-in vivo correlations for danazol hard-gelatin capsules using the flow through cell apparatus, media simulating the intraintestinal composition, and flow rates higher than the physiological, in other words, at least $8 \mathrm{~mL} / \mathrm{min}$ (12). To compensate for the resulting high (non-physiologically relevant) total fluid volumes, the experiments were extended for 2 hours. It is interesting to note that, with this methodology, point-topoints in vitro-in vivo correlations were developed under both fasted and fed conditions; whereas correlations in the fed state were better when lipid digestion products had been included in the relevant release media.

\subsection{Extended release dosage forms}

Originally, the flow through cell apparatus had been thought to facilitate development of in vitro-in vivo correla- 

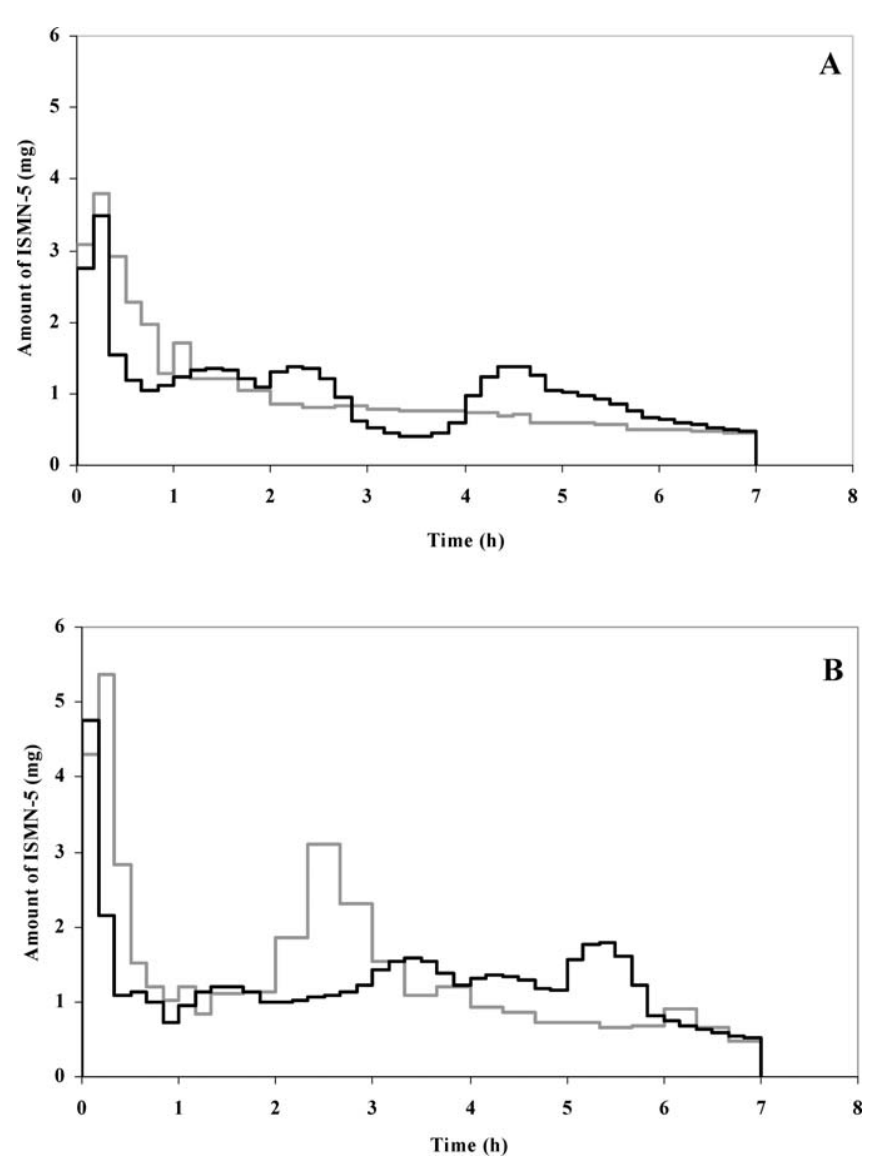

Figure 1. Mean amounts of isosorbide-5-mononitrate (ISMN-5) released in vitro (-) and absorbed from the human gastrointestinal tract (-) at 10minute intervals up to 7 hours after the initiation of each process. (A) Imdur ${ }^{T M}$; (B) osmotic pump. (Reprinted from ref. 33 with permission from Elsevier)

tions for extended release products. Based on the literature data, these correlations are limited, and the data may not be suitable for publication. When Möller and Langenbucher studied release of aminophylline extended release tablets with the paddle and the flow through cell apparatus, they could observe the effect of the $\mathrm{pH}$ of the medium on the in vitro release only with the flow through cell apparatus (31). Based on the in vivo release data, they concluded that the increased inter- and intra-individual variation was due to the $\mathrm{pH}$-dependent release characteristics (31).

Similarly, Emara et al. (32) showed that for ER formulations of vincamine (a compound with $\mathrm{pH}$-dependent dissolution characteristics) the in vitro release data with the flow through apparatus could be correlated point-to-point with in vivo data only if used as an open system (32). The release was monitored in simulated gastric fluid without enzyme ( $\mathrm{pH} 1.2,0-1 \mathrm{~h}$ and $\mathrm{pH} 4.5,1-2 \mathrm{~h}$ ) and simulated intestinal fluid without enzyme ( $\mathrm{pH} 6.9,2-4 \mathrm{~h}$ and $\mathrm{pH} 7.5,4-5 \mathrm{~h})$ at $8 \mathrm{~mL} / \mathrm{min}$. It is interesting to note that with the specific experimental setup, sink conditions were maintained throughout the experimental period (32).

Fotaki et al. (33) were able to develop a point-to-point correlation of in vitro release data using the flow through
Table 2: Fasted state simulating luminal conditions for the in vitro release testing of monolithic extended release dosage forms with the flow-through cell apparatus (33).

\begin{tabular}{|ccc|}
\hline Medium & $\begin{array}{c}\text { Period } \\
(\mathbf{m i n})\end{array}$ & $\begin{array}{c}\text { Flow rate } \\
(\mathbf{m L} / \mathbf{m i n})\end{array}$ \\
\hline SGF & $0-60$ & 8 \\
\hline FaSSIF & $60-270$ & 4 \\
\hline SCoF & $270-420$ & 4 \\
\hline
\end{tabular}

cell apparatus with the in vivo absorption data of two monolithic extended release formulations of a highly soluble highly permeable compound (isosorbide-5-mononitrate) in fasted state by using physiologically relevant media and physiologically relevant flow rates (Table 2 ). It is worth noting that in this study in vitro release data were also collected in a new medium that simulated the contents of the ascending colon. There are several attempts to simulate the contents of the lower part of the gastrointestinal tract. In the literature, primarily phosphate buffers with $\mathrm{pH}$ values of 7 to 7.5 have been proposed for this simulation (34-38). The $\mathrm{pH}$ in the first part of the large intestine has been reported to range with time and food intake from 4.8 to 7 (39-44). Furthermore, acetate, propionate and butyrate are the principal organic anions found in colonic contents (45). Based on these data, an acetate buffer with a $\mathrm{pH}$ value of 5.8 has been used for simulating the contents of the proximal colon (33). Figure 1 shows that the mean amounts of isosorbide-5mononitrate released in vitro and absorbed in humans every 10 minutes are similar. The same was true for the associated confidence intervals (33). It is interesting to note that, unlike with the immediate release products, the physiologically relevant flow rates did not lead to underestimation of the in vivo release from the extended release products of isosorbide-5-mononitrate. This is most likely related to the fact that extended release products are generally less sensitive to changes in agitation intensity.

\section{CONCLUDING REMARKS}

Literature data suggest that, due to a number of advantages compared to closed systems, the flow through cell apparatus can be used to assess intralumenal disintegration of dosage forms. In addition, raw dissolution data can be directly correlated with appropriate in vivo data of poorly soluble compounds and of highly soluble - highly permeable compounds housed in extended release products. The limited use of the flow through cell apparatus, in the evaluation of intralumenal drug release characteristics to date seems to be related to poorly defined optimum operating conditions.

\section{REFERENCES}

1. Vliet, E.B., Letter sent to the U.S.P. Subcommittee on Tablets (August 23), 1957.

2. Langenbucher, F., Benz, D., Kürth, W., Möller, H., Otz, M. 
Standardized flow-cell method as an alternative to existing pharmacopoeial dissolution testing. Pharm. Ind. 51, 1276-1281, 1989.

3. Rippie, E.G., Johnson, J.R. Regulation of dissolution rate by pellet geometry. J. Pharm. Sci. 51, 428-431, 1969.

4. Langenbucher, F. In vitro assessment of dissolution kinetics: description and evaluation of a column-type method. J. Pharm. Sci. 58 (10), 1265-1272, 1969.

5. Lerk, C.F., Zuurman, K. The influence of pulsation on the dissolution rate measurements in column type apparatus. J. Pharm. Pharmacol. 22 (4), 319-320, 1970.

6. Groves, M.J., Alkan M.H., Deer, M.A. The evaluation of a column-type dissolution apparatus. J. Pharm. Pharmacol. 27 (6), 400-407, 1975.

7. Langenbucher, F., Retting, H. Dissolution rate testing with the column method: methodology and results. Drug Dev. Ind. Pharm. 3 (3), 241-263, 1977.

8. USP 26-NF 21. The United States Pharmacopeia-The National Formulary. Rockville MD, 20852, The United States Pharmacopeial Convention, Inc., 2003.

9. Möller, H. Dissolution testing of different dosage forms using the flow through method. Pharm. Ind. 45, 617622, 1983.

10. Bhattachar, S.N., Wesley, J.A., Fioritto, A., Martin, P.J., Babu, S.R. Dissolution testing of a poorly soluble compound using the flow through cell dissolution apparatus. Int. J. Pharm. 236, 135-143, 2002.

11. Sunesen, V.H., Vedelsdal, R., Kristensen, H.G., Christrup, L., Müllertz, A. Effect of liquid volume and food intake on the absolute bioavailability of a poorly soluble drug, danazol. Eur. J. Pharm. Sci. 24(4), 297-303, 2005.

12. Sunesen, V.H., Pedersen, B.L., Kristensen, H.G., Müllertz, A. In vivo in vitro correlations for a poorly soluble drug, danazol, using the flow through dissolution method with biorelevant dissolution media. Eur. J. Pharm. Sci., 24 (4), 305-13, 2005.

13. Moog, F. The lining of the small intestine. Scientific American, November issue, 116-125, 1981.

14. Ishii, K., Saito, Y., Itai, S., Takayama, K., Nagai, T. In vitro dissolution test corresponding to in vivo dissolution of sofalcone formulations. S.T.P. Pharma Sci. 7 (4), 270276, 1997.

15. Nicolaides, E., Symillides, M., Dressman, J.B., Reppas, C. Biorelevant dissolution testing to predict the plasma profile of lipophilic drugs after oral administration. Pharm. Res. 18, 380-388, 2001.

16. Özdemir, N., Ordu, S., Özkan, Y. Studies of floating dosage forms of furosemide: in vitro and in vivo evaluations of bilayer tablet formulations. Drug Dev. Ind. Pharm. 26 (8), 857-866, 2000.

17. Fotaki, N., Vertzoni, M., Dressman, J.B., Reppas, C. Optimising the in vitro conditions to simulate the release process in stomach after meals, [6th European Congress of Pharmaceutical Sciences, Budapest], Eur. J. Pharm. Sci. (Suppl.1) 11, S44, 2000.

18. Vertzoni, M., Iliadis, A., Nicolaides, E., Symillides, M., Reppas, C. Orally administered drug products: dissolu- tion data analysis with a view to IVIVC, Chapter 8, Dressman JB and Kraemer J (Eds.), Taylor and Francis Books, (ISSN/ISBN 0-8247-5467-0), pp. 227-248, 2005.

19. Amidon, G.L., Lennernas, H., Shah, V.P., and Crison, J.R. A theoretical basis for a Biopharmaceutics drug classification: the correlation of in vitro drug product dissolution and in vivo bioavailability. Pharm. Res 12 (3), 413420, 1995.

20. Kalantzi, L., Nicolaides, E., Page, R.C., Digenis, G.A., Reppas, $C$. Prediction of the average plasma profile after oral administration of cross-linked gelatin capsules of amoxicillin, Poster presentation, International Symposium on scientific and regulatory aspects of dissolution and bioequivalence, Athens, 2002.

21. Vertzoni, M., Dressman, J., Butler, J., Hempenstall, J., Reppas, C. Simulation of fasting gastric conditions and its importance for the in vivo dissolution of lipophilic compounds. Eur. J. Pharm. Biopharm., in press, 2005.

22. Galia, E., Nicolaides, E., Hoerter, D., Loebenberg, R., Reppas, C., Dressman, J.B. Evaluation of various dissolution media for predicting in vivo performance of class I and II drugs. Pharm. Res. 15, 698-705, 1998.

23. Digenis, G.A., Sandefer, E.P., Page, R.C., Doll, W.J., Gold, T.B., Darwazeh, N.B. Bioequivalence study of stressed and nonstressed hard gelatin capsules using amoxicillin as a drug marker and gamma scintigraphy to confirm time and Gl location of in vivo capsule rupture. Pharm. Res., 17(5) 572-582, 2000.

24. Kalantzi, L., Polentarutti, B., Albery, T., Laitmer, D., Abrahamsson, B., Dressman, J., Reppas, C. The delayed dissolution of paracetamol products in the canine fed stomach can be predicted in vitro but it does not affect the onset of plasma levels. Int. J. Pharm., 296(1-2), 87-93, 2005.

25. Macheras, P., Koupparis, M., Tsaprounis, C. Drug dissolution studies in milk using the automated flow injection serial dynamic dialysis technique. Int. J. Pharm. 33, 125136, 1986.

26. Kelly, K., O'Mahony, B., Lindsay, B., Jones, T., Grattan, T., Rostami-Hodjegan, A., Stevens, H.N.E., Wilson, C.G. Comparison of the rates of disintegration, gastric emptying, and drug absorption following administration of a new and a conventional paracetamol formulation, using g-scintigraphy. Pharm. Res. 20, 1668-1673, 2003.

27. Bonlokke, L., Hovgaard, L., Kristensen, H.G., Knutson, L., Lennernas, $H$. Direct estimation of the in vivo dissolution of spironolactone, in two particle size ranges, using the single-pass perfusion technique (Loc-I-Gut) in humans. Eur J Pharm Sci. 12 (3), 239-50, 2001.

28. Nicolaides, E., Hempenstall, J.M., Reppas, C. Biorelevant dissolution tests with the flow through apparatus? Dissolution Technologies 7 (1), 8-11, 2000.

29. Bonlokke, L., Hovgaard, L., Kristensen, H.G., Knutson, L., Lindahl, A., Lennernas, $H$. A comparison between direct determination of in vivo dissolution and the deconvolution technique in humans. Eur J Pharm Sci. 8 (1), 19$27,1999$. 
30. Dressman, J.B., Amidon, G.L., Reppas, C., Shah, V. P. Dissolution testing as a prognostic tool for oral drug absorption: immediate release dosage forms. Pharm.Res. 15, 11-22, 1998.

31. Möller, H., Langenbucher, F. In vitro and in vivo dissolution of some sustained release tablets of theophylline. Pharm. Ind. 44 (10), 1065-1071, 1982.

32. Emara, L.H., El-Menshawi, B.S., Estefan, M.Y. In vitro-in vivo correlation and comparative bioavailability of vincamine in prolonged-release preparations. Drug Dev. Ind. Pharm. 26 (3), 243-251, 2000.

33. Fotaki, N., Symillides, M., Reppas, C. In vitro vs. canine data for predicting input profiles of isosorbide-5mononitrate from oral extended release products on a confidence interval basis. Eur. J. Pharm. Sci., 24, 115$122,2005$.

34. Randall, J.M. The colon as a site for drug delivery. J. Control. Release 22, 15-34, 1992.

35. Ashford, M., Fell, J., Attwood, D., Woodhead, P. J. An in vitro investigation into the suitability of $\mathrm{pH}$-dependent polymers for colonic targeting. Int. J. Pharm. 91, 241245, 1993.

36. Ashford, M., Fell, J. Targeting drugs to the colon: delivery systems for oral administration. J. Drug Target. 2 (3), 241-257, 1994.

37. Rodriguez, M., Vila-Jato, J.L., Torres, D. Design of a new multiparticulate system for potential site-specific and controlled drug delivery to the colonic region. J.
Control. Release 55 (1), 67-77, 1998.

38. Cole, E., Scott, R., Connor, A., Wilding, I, Petereit, H.U., Schminke, C., Beckert, T., Cade, D. Enteric coated HPMC capsules designed to achieve intestinal targeting. Int. J. Pharm. 231, 83-95, 2002.

39. Elkington, S.G. Lactulose. Gut 11, 1043-1048, 1970.

40. Gruber, P., Longer, M.A., Robinson, J.R. Some biological aspects in oral, controlled drug delivery. Adv. Drug Deliv. Rev. 1, 1-18, 1987.

41. Evans, D.F., Pye, G., Bramley, R., Clark, A.G., Dyson, T.J., Hardcastle, J.D. Measurement of gastrointestinal $\mathrm{pH}$ profiles in normal ambulant human subjects. Gut 29, 1035-1041, 1988.

42. Macfarlane, G.T., Cummings, JH. The colonic flora, fermentation, and large bowel digestive function. In: Phillips, S.F., Pemberton, J.H., Shorter R.G. (Eds.), The Large Intestine: Physiology, Pathophysiology, and Disease, chapter 4, Mayo Foundation, Raven Press, New York, pp. 51-92, 1991.

43. Press, A.G., Hauptmann, I.A., Hauptmann, L., Fuchs, B., Fuchs, M., Ewe, K., Ramadori, G. Gastrointestinal pH profiles in patients with inflammatory bowel disease. Aliment. Pharmacol. Ther. 12,673-678, 1998.

44. Nugent, S.G., Kumar, D., Rampton, D.S., Evans, D.F. Intestinal luminal $\mathrm{pH}$ in inflammatory bowel disease: possible determinants and implications for therapy with aminosalicylates and other drugs. Gut 48 (4), 571$577,2001$. 